\title{
Aflatoxin Contamination of Coconut Oil from small scale Mills: Toxin Levels and their Relation to Free Fatty Acid Content
}

\author{
U. SAMARAJEEWA, T. V. GAMAGE
}

Department of Agricultural Chemistry, Faculty of Agriculture, University of Peradeniya, Peradeniya, Sri Lanka.

AND

S. N. ARSECULERATNE*

Department of Microbiology, Faculty of Medicine, University of Peradeniya, Peradeniya, Sri Lanka.

(Date of receipt: 30 May 1983)

(Date of acceptance: 14 December 1983)

\begin{abstract}
Coconut oil which was mechanically extracted in small scale mills, from intermittently processed (sun-dried or smoked) Grade III or substandard copra kernels, was assayed for free fatty acid and aflatoxin Bl. Oil from these samples showed significantly high levels of aflatoxin Bl (mean value $186 \mathrm{ppb}$ in 115 samples of oil) than the levels found in oil from adequately processed copra extracted in large scale industrial mills. The attention of the coconut industry is drawn to this problem as a potential health hazard to humans and animals, from the consumption of the oil and press cake from such inadequately processed kernels.

The relationship between free fatty acid (FFA) content and aflatoxin Bl levels in 100 samples of coconut oil from the small scale mills has been investigated. No correlation was found. The conventionally used FFA content as a chemical index of the 'quality' of oil does not reflect the degree of aflatoxin contamination, making it necessary to apply separate assays for aflatoxin contamination in coconut oil, from commercial sources. Possible reasons for the absence of a correlation between FFA and aflatoxin levels in such oils are discussed.
\end{abstract}

\section{Introduction}

In recent years, new small scale rural oil extracting mills have been set up in Sri Lanka, for extracting coconut oil from domestically cured copra. The latter kernels are those which have been rejected by large industrial mills. We hypothesised that the incomplete and inadequate curing of these kernels with consequent fungal spoilage might result in higher degree of aflatoxin contamination than is found in oil extracted from adequately cured copra, in large industrial mills. In this study, the aflatoxin levels in oil from these small scale mills were estimated and compared with the levels of toxin which were detected in oil from the large commercial mills in a previous study. ${ }^{9}$ The aflatoxin levels in some of the oil samples from domestically cured copra

\footnotetext{
* Present address - Department of Medical Microbiology, Faculty of Medicine, University of Malaya, Kuala Lumpur.
} 
extracted in the small mills were appreciably higher than those found in the oil from the large industrial mills, indicating that the domestic curing of kernels entails a potential hazard through inadequate curing and fungal spoilage of kernels, which merits early attention.

The free fatty acid (FFA) content is one of the most widely used chemical indices of the quality of cemmercial coconut oil. This index reflects the hydrolysis of the main lipid constituent, the triglycerides, principally by microbial (bacterial and fungal) lipases in the original copra. The lipolysis results in heavy economic losses to the coconut industry in respect of both the loss of lipid and the quality of the oil and residual meal (press cake).

With the discovery of aflatoxins as potent hepatotoxic and carcinogenic substances, and their frequent occurrence in oil seeds, the assay of aflatoxin levels in oil seed products (mainly oil and press cake) assumed great economic and biological importance. These assays are however time-consuming and expensive. Since the predominant cause of FFA accumulation in oil seeds is the lipolytic activity of contaminant micro-organisms which include fungi, notably aspergilli which are also the source of aflatoxin, it was considered useful to investigate the relation between FFA levels and aflatoxin, since a positive correlation between these two indices may make the conventional FFA estimation, a simultaneous indicator of aflatoxin contamination. No correlation was found and this absence is discussed in terms of the origin and fate of aflatoxin and FFA in coconut oil.

\section{Experimental}

\subsection{Coconut oil.}

50-100 g samples of oil were obtained from 3 small scale private rural mills in the Kuliyapitiya District. Each sample had been mechanically expelled from a $10-50 \mathrm{~kg}$ batch of copra kernels. These copra kernels had been processed domestically by rural folk, the majority of kernels having been sundried without the conventional smoke treatment which is applied on copra kernels in large scale industrial mills. The domestically cured kernels were generally of Grade III or discards which were rejected by the large mills. Further details of the processing of these substandard kernels are discussed below.

The samples of oil were collected into dark glass bottles to minimise exposure to light and were stored at $4^{\circ} \mathrm{C}$ in the dark pending FFA and aflatoxin assay.

2.2 Aflatoxin assay. The oil with its particulate deposit which formed on standing, was well homogenised by manual shaking. Ten $g$ aliquots in duplicate were extracted by the aqueous acetone method. ${ }^{8}$ Extracts of aflatoxin in chloroform were titrated on $250 \mathrm{~nm}$ TLC plates which were developed in $3 \%$ methanol in chloroform, by visual 
comparison with standard inocula of pure aflatoxin $B 1$ in chloroform. under $365 \mathrm{~nm}$ () $V$ light. Aflatoxin Gl was not estimated since its occurrence was infrequent in the samples tested.

\subsection{FFA determination}

About 10 g of oil was weighed accurately into $50 \mathrm{ml}$ of $96 \%$ cthanol. Phenolphthalcin indicator $(0.5 \mathrm{ml})$ was added and the mixture was heated to boiling point in a water bath. The hot solution was titrated against $0.1 \mathrm{~N}$ potassium hydroxide until a pink colour which persisted for $15 \mathrm{sec}$ appeared to signify the end point of the titration.

\section{Results}

\subsection{FFA levels}

The frecuency distribution of FFA levels in the 100 samples of oil cxamined, is shown in Figure 1: the modal value was between 0.5 and $1 \%$ in a lange from 0.33 to $19.25 \%$. The mein I:FA content of the series was $3.56 \%$.

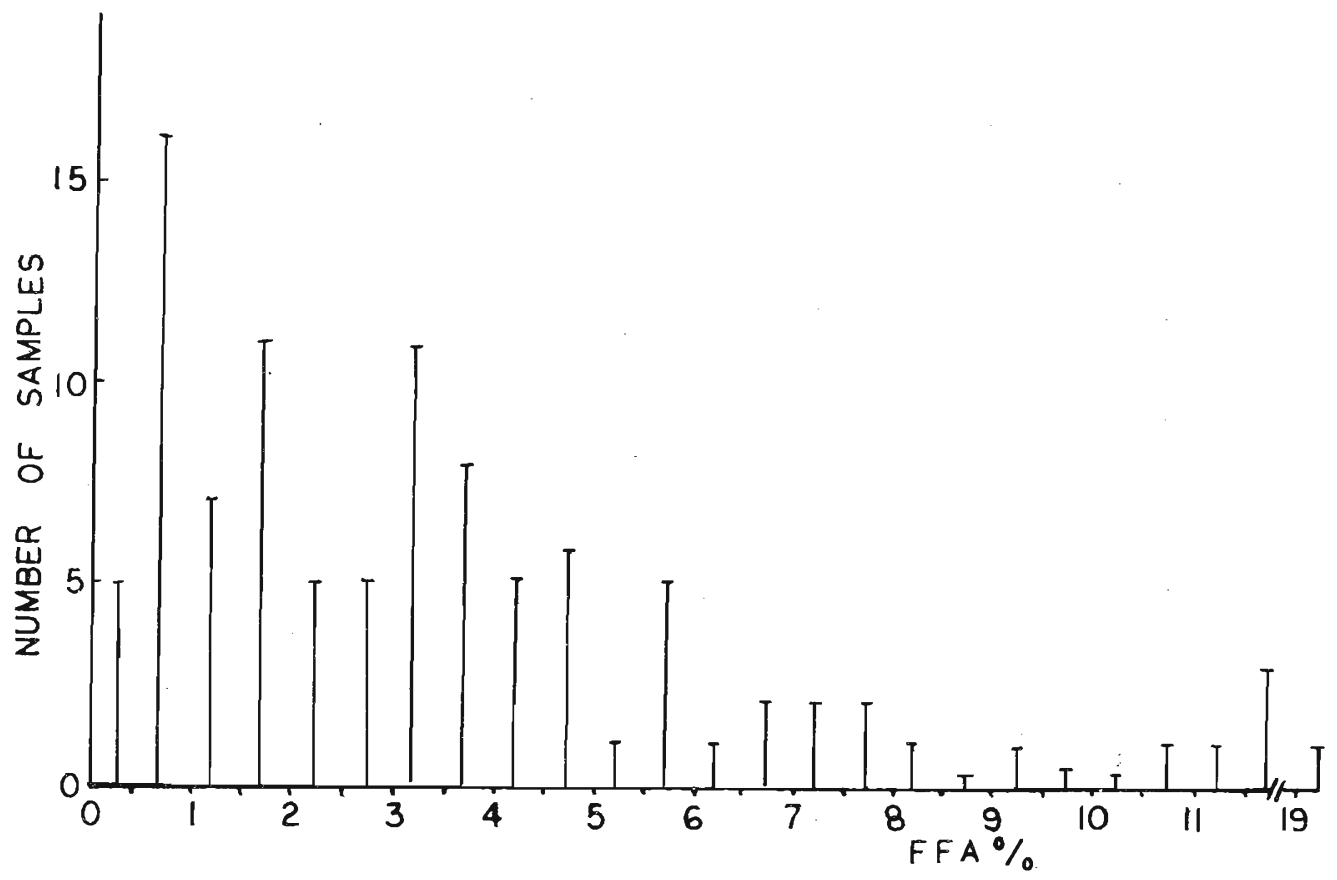

Figure 1. Frequency distribution of free fattyacid (FFA) levels (expressed as a percentage by weight) in 100 samples of coconut oil. mechanically extracted from substandard copra kernels. 


\subsection{Aflatoxin levels}

The frequency distribution of the aflatoxin B1 levels in 105 samples of oil, is shown in Figure 2. The values ranged from 0 (below $1 \mathrm{ppb}$ ) to $250 \mathrm{ppb}$. In 10 further samples the levels ranged from $500 \mathrm{ppb}(5$ samples $)$ through 1000, 1750, 2000, 3000 to $5000 \mathrm{ppb}$. The mean aflatoxin B1 content of the 115 samples was $186 \mathrm{ppb}(\mu \mathrm{g} / \mathrm{kg})$. This valuc is significantly high at $5 \%$ level in comparison to mean value for large scale mills.

\subsection{Correlation between FFA content and Aflatoxin B1 content}

Figure 3 shows the relationship between the FFA content $(\%)$ and aflatoxin B 1 concentrations $(k g \mathrm{~kg}$ ppb) in 100 samples of oil. There was no correlation between these $(w 6)$ indices $(r=+0.06+8)$.

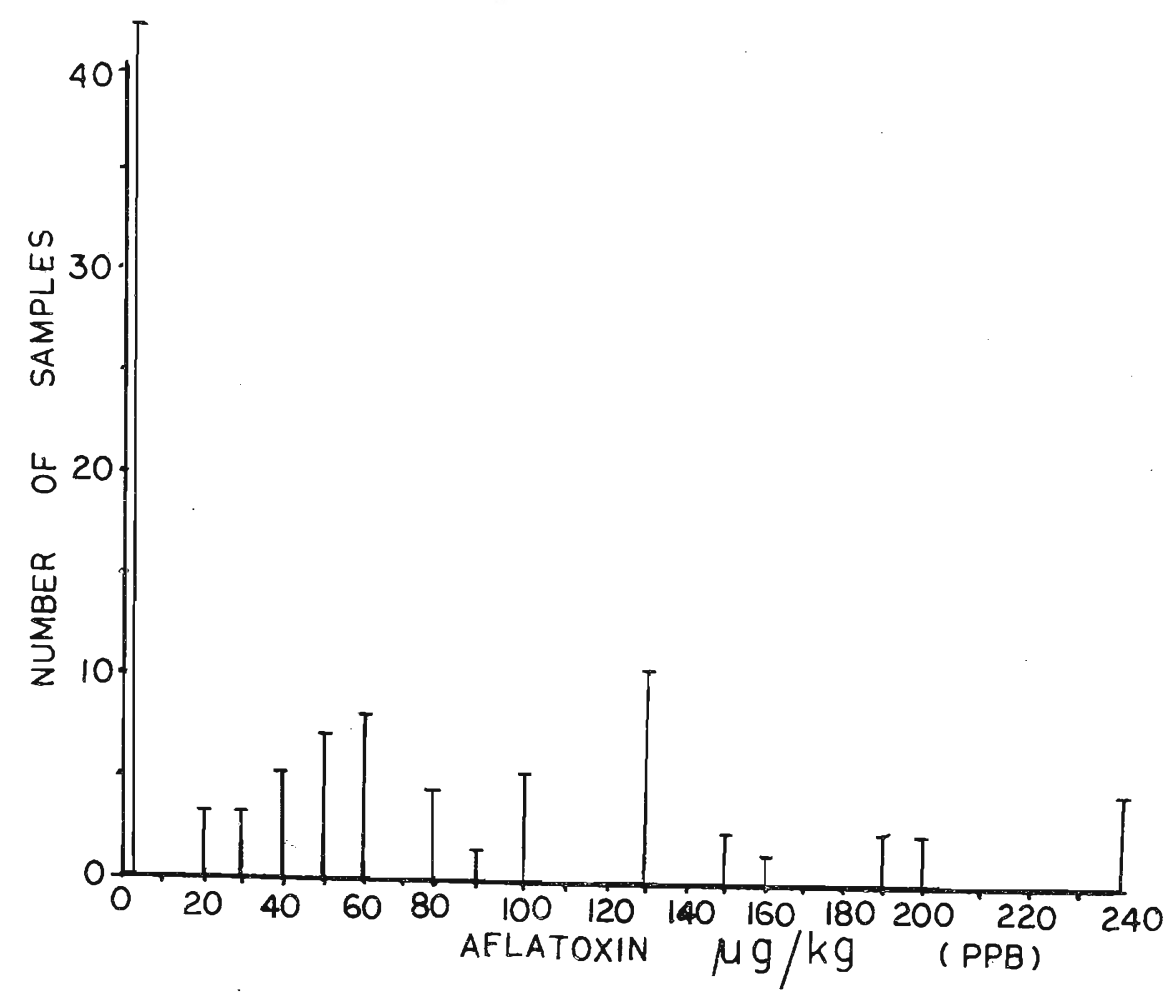

Figure 2. Frequency distribution of Aflatoxin Bl levels $(\mu \mathrm{g} / \mathrm{kg}$ parts per billion-PPB) in 105 samples of coconut oil, mechanically extracted from substandard copra kernels. 


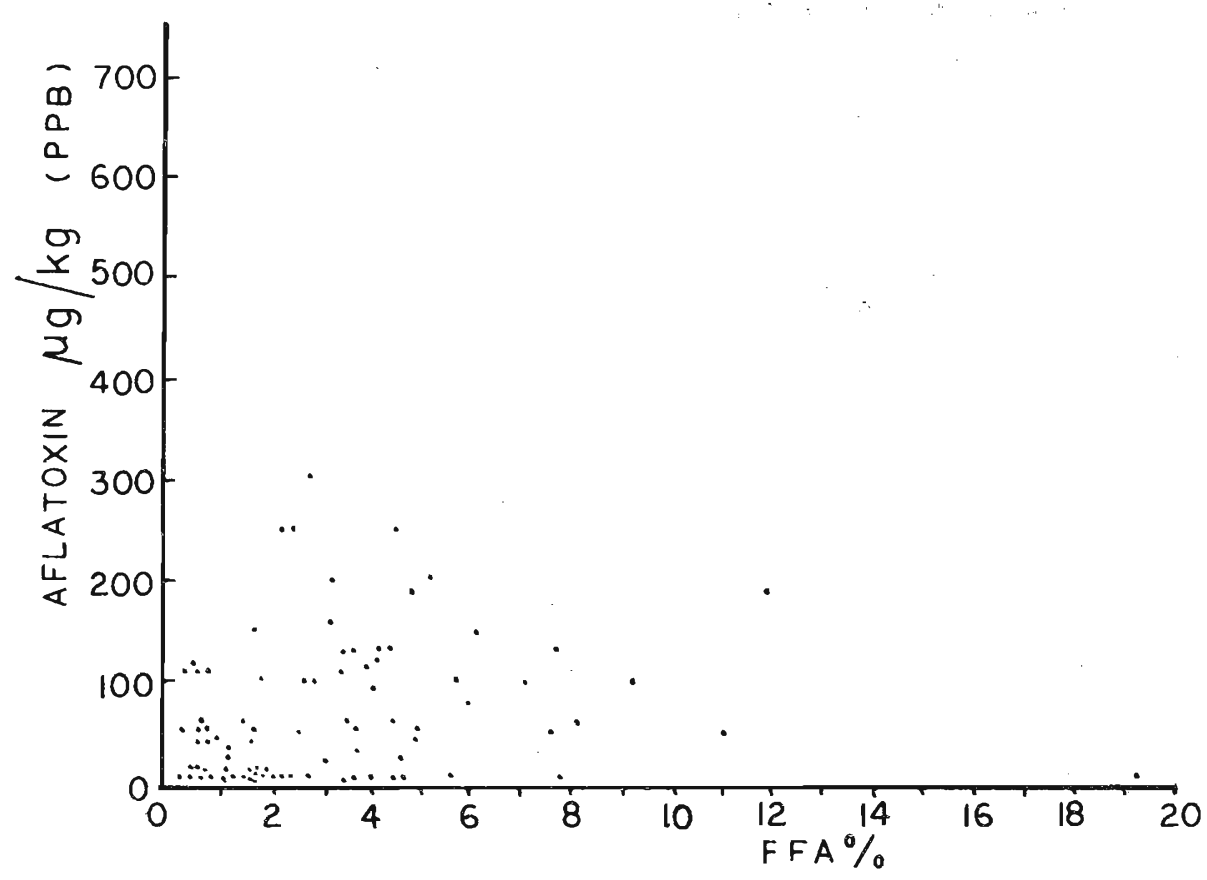

I'igure 3. Relationship between free fatty acid (FFA) content ( $/$ ) and Aflatoxin Bl levels (PPB) in IOO) samples of coconut oil. mechanically extracted fromsubstandard copra kernels.

\subsection{Aflatoxin B1 levels}

\section{Discussion}

Samarajecwai concluded from an extensive survey of aflatoxin contamination of industrial coconut products (mainly oil, copra and copra press cake) that an appreciable proportion of the samples of oil which were processed during the dry or wet seasons had cconomically significant levels of aflatoxin B1 with reference to the recommended permissible maximum of $30 \mathrm{ppb}(\mu \mathrm{g} / \mathrm{kg})$ of aflatoxin Bl (WHO/FAO/UNIClEF). Thesc coconut oil samples were derived by mechanical extraction from copra processed in large industrial mills. From 116 samples of coconut oil which were collected during the wet and dry scasons in 1973, the mean level of aflatoxin B 1 detected was $50 \mathrm{ppb}$ with a range from 0 to $400 \mathrm{ppb}$. Nonc of the samples had levels above $400 \mathrm{ppb}$. In contrast, the mean ievel of aflatoxin B 1 detected in the present study of 115 samples from small scalc mills in the same district was $186 \mathrm{ppb}$ with 10 samples having had levels of $500 \mathrm{ppb}$ ( 5 samples) or more (5 samples having had 1000, 1750, 2000, 3000) and 5000 ppb icspectively). 
Coconut oil is extracted from smoke cured copra in Sri Lanka, mainly by large scale industrial mills which use power driven mechanical expellers. Small quantities of oil for domestic use were extracted in stone mills ('sekku') at the village level three to four years ago. At the household level oil, was extracted by the traditional technique of boiling aqueous homogenates of coconut milk and decanting the supernatant oil after separation of the phases on standing. However, with the extension of electrification to rural areas, numerous small scale mills have been set up for the extraction of oil by electrically powered mechanical expellers. The starting material for these small mills is copra which has been 'cured' domestically. The majority of these kernels hau been merely dried by exposure to sunlight whenever available; this process was therefore intermittent and excluded smoke treatment. A small proportion of the kernels was smoked in domestic kitchens on shelves above the hearth. Hence as with sunlight exposure, the smoking was intermittent allowing of fungal colonisation during the intervening periods. The promotion of the growth of Aspergillus flavus in broth by low degrees of smoking (whereas higher degrees of smoking inhibit the growth) was reported by Samarajeewa. 9

In addition to such improper or inadequate curing, domestically processed copra has the added disadvantage of improper storage leading to insect and rodent attack which promote fungal colonisation.

Such factors in the curing and storage of copra kernels are the probable explanation for the higher levels of aflatoxin which were detected in oil which was extracted from these domestically processed kernels.

The consequences of such contamination are however not economically significant in relation to the export market since these products (oil and press-cake) are solely for domestic use in the villages. The notable effect of this contamination would on the other hand be in relation to intoxication of human and farm animal populations which consume the oil and press cake derived from such substandard copra kernels.

The health hazard posed by domestically processed copra is heightened by two factors. (a) The contaminated kernels in domestic batches are not mixed as in the large mills, with non-mouldy kernels, with the result that the aflatoxin levels are not reduced by dilution; (b) the consumers of these products are either the rural folk who process these kernels for their own use or are those living in the vicinity of the mills, both categories of persons being regularly exposed to such contaminated oil. This is in contrast to the products from the large mills which are distributed by sale in a wider area both within and outside the district making it less likely that consistently contaminated oil or press cake is consumed by humans or animals in a restricted locality. 
4.2 Relation between aflatoxin and FFA levels. Eyre ${ }^{4}$ reported that of 13 strains of Aspergilli from mouldy copra which were tested, all had lipolytic activity. Hiscocks ${ }^{6}{ }^{6}$ noted that $A$. flavus in common with Aspergillus niger, Aspergillus fumigatus and Aspergillus awamori had marked lipolytic activity among 9 species of Aspergilli tested. Since strains of Aspergillus flavus-parasiticus are the source of the aflatoxins and are common contaminants in mouldy copra, it is theoretically possible that a proportionality between levels of FFA as hydrolytic products of lipolytic activity and aflatoxin may be found. This expectation is supported by the demonstration that both . glycerol ${ }^{2}$ and fatty acids especially lauric acid ${ }^{5}$ which is a major constituent of coconut triglyceride, are promoters of aflatoxin production. Pattee and Sessoms ${ }^{7}$ reported a correlation between fungal growth score and both fatty acid and aflatoxin concentrations in peanuts which had been experimentally inoculated with an aflatoxigenic strain of A.flavus. Diener and Davis ${ }^{3}$ however found no correlation between free fatty acid and aflatoxin in experimental cultures on peanuts.

The conclusion from the present study that no proportionality existed between the FFA and aflatoxin levels in field samples of coconut oil, may be explained on the basis of several considerations :-

(a) While strains of A.flavus tested by Eyre ${ }^{4}$ and Hiscocks 6 were markedly lipolytic, only a proportion (approximately $75 \% \%^{6}$ or $43 \% \%^{1}$ ) are aflatoxigenic. Hence contamination with A.flavus would result more uniformly in the accumulation of free fatty acid than of aflatoxin. Moreover other species of contaminating Aspergilli, some of which are also actively lipolytic, could also contribute to the FFA content but not to a parallel increase of the aflatoxin concentration.

(b) Apart from fungal lipases, bacterial and endosperm lipases and spontaneous non-enzymatic hydrolysis may also increase the FFA levels, in copra and the derivative oil. Such FFA release will not be paralleled by an increase of the aflatoxin level.

(c) It has been shown that the aflatoxin level in contaminated coconut oil decreases with age of the oil ${ }^{1}$ resulting probably from exposure to daylight. ${ }^{9}$ The FFA level will conversely tend to increase due to the action of residual lipases derived from the original kernel.

Thus the multiplicity of factors which increase the FFA level is in contrast to the single source of aflatoxin and this together with the non-parallelism of the increase or decrease of the levels of these two components, could in our opinion explain the absence of a correlation between the FFA and aflatoxin levels in coconut oil.

\section{Acknowledgements}

We are thankful to the Natural Resources, Energy \& Science Authority of Sri Lanka for research grants (RG/79/19 and 83/27) and to Mr. Y. W. Pemasinghe for technical assistance. 


\section{References}

1. ARsecul.eratne. S. N. \& de Silva. L. M. (1971). Cey. J. Medi, Sci., 20.60.

2. DAVIS. N. D. \& DIENER. U. L. (1968). Appl. Microbiol., 16.: 158.

3. DIENER. U. L. \& DAVIS. N. D. (1967). J. Amer. Oil Chem. Soc., 44:259.

4. EYRE. J. C. (1932). Annal.Appl.Biol., 19:351.

5. GUPTA. S. R.. PRASANNA. H. R. VISWANATHAN. L. \& VENKITASUBRAMANIAN. (1974) Experientia,: 30: 1244

6. HISCOCKS. E. S. (1965). In Mycotoxins in Foodstuffs, 15 p. Ed. G.N. Wogan, Camb. Mass.. M.I.T. Press.

7. PATTEE, H. E. \& SESSOMS, S.L. (1967). J. Amer. Oil Chem. Soc., 44; 61.

8. PONS, W. A. Jr., CUCUllu, A. F., LEE, L. S., ROBERTSON, J. A., FRANZ, A. O. \& GOldelatT, L. A. (1966). J. Assoc. Off. Agric. Chem., 49, 554.

9. SAMARAJEEWA, U. (1975). Mycotoxins in Coconut based human and Animal foodstuffs. Ph.D. Thesis, University of Peradeniya, Sri Lanka. 